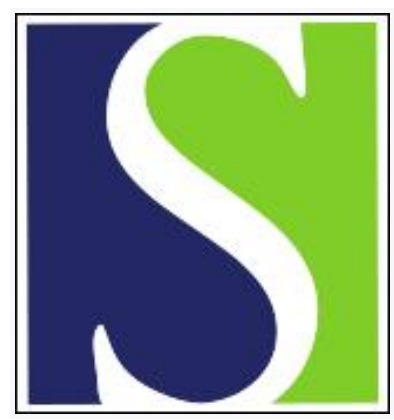

Scand J Work Environ Health 2007;33(1):45-50

https://doi.org/10.5271/sjweh.1063

Issue date: 31 Feb 2007

Effect of shift work on body mass index and metabolic parameters

by Morikawa Y, Nakagawa H, Miura K, Soyama Y, Ishizaki M, Kido T, Naruse $Y$, Suwazono $Y$, Nogawa $K$

Affiliation: Department of Epidemiology and Public Health, Kanazawa Medical University, 1-1 Daigaku, Uchinada-machi, Kahoku-gun, Ishikawa 920-0293, Japan. ymjr@kanazawa-med.ac.jp

Refers to the following texts of the Journal: 1999;25(2):85-99

2002;28(1):64-71 2001;27(2):87-96 2001;27(5):318-326

1999;25(2):100-104 2005;31(3):179-183

The following articles refer to this text: 2008;34(1):33-39;

2008;34(3):198-205; 2009;35(4):309-318; 2010;36(2):109-121;

2010;36(6):515-516; 2011;37(4):263-275; 2015;41(1):84-93;

2018;44(3):251-257; 2019;45(4):402-412

Key terms: blood pressure; body mass index; cholesterol; cohort study; glycosylated hemoglobin; metabolic parameter; shift work

This article in PubMed: www.ncbi.nlm.nih.gov/pubmed/17353964 


\title{
Effect of shift work on body mass index and metabolic parameters
}

\author{
by Yuko Morikawa, PhD, ${ }^{1}$ Hideaki Nakagawa, PhD, ${ }^{1}$ Katsuyuki Miura, PhD, ${ }^{1}$ Yoshiyuki Soyama, PhD, 1 \\ Masao Ishizaki, PhD, ${ }^{2}$ Teruhiko Kido, PhD, ${ }^{3}$ Yuchi Naruse, PhD, ${ }^{4}$ Yasushi Suwazono, PhD, ${ }^{5}$ Koji Nogawa, \\ $P h D^{5}$
}

\begin{abstract}
Morikawa Y, Nakagawa H, Miura K, Soyama Y, Ishizaki M, Kido T, Naruse Y, Suwazono Y, Nogawa K. Effect of shift work on body mass index and metabolic parameters. Scand J Work Environ Health 2007;33(1):45-50.
\end{abstract}

Objectives The aim of this cohort study was to investigate the effects of shift work on changes in parameters related to metabolic disturbances.

Methods The study population included 1529 male blue-collar workers, aged 19-49 years at baseline, working in a sash and zipper factory in Japan. The participants were divided into four groups according to the work schedule at baseline, the end point being workers doing fixed daytime work in both years (day-day), workers who changed from shift work to fixed daytime work (shift-day), workers who changed from fixed daytime work to shift work (day-shift), and workers doing shift work in both years (shift-shift). The changes in body mass index (BMI), blood pressure, serum cholesterol, and glycosylated hemoglobin A1c over a period of 10 years were compared among the groups by work schedule.

Results The age-adjusted mean increase in BMI was $1.03 \mathrm{~kg} / \mathrm{m}^{2}$ for the day-shift workers, and it was significantly larger than that of the day-day workers and shift-day workers. The shift-shift workers showed a significantly larger increase in BMI than the day-day workers. These tendencies remained after adjustment for age and all other confounding factors, such as BMI, smoking, drinking, and leisure-time physical activity at baseline. The increase in total cholesterol tended to be higher among the shift-shift workers and the day-shift workers, but there were no significant differences. Blood pressure and hemogrlobin A1c did not differ among the four groups.

Conclusions Shift work is considered to be a risk factor for excess weight. However, no significant difference in the biomarkers was found between daytime workers and shift workers.

Key terms blood pressure; cholesterol; cohort study; glycosylated hemoglobin.

Shift work has been associated with an increased risk of cardiovascular disease (CVD) (1-3). Four pathwaysmismatch of circadian rhythms, social disruption, behavioral changes, and changes in biomarkers-are considered to be the factors that predispose shift workers to CVD (1). The pathway of changes in biomarkers has been investigated in many studies. However, because of the limited number of longitudinal designs, this pathway remains unclear (1). Overall, among the studies of the relationship of shift work to the metabolism of lipids, glucose tolerance, and obesity, negative studies are numerically superior (1). Recently, more cross-sectional studies have revealed that shift workers have a higher prevalence or a higher level of biomarkers of CVD (4-9). The results of short-term prospective studies were inconsistent $(10,11)$. Both a decrease and an increase in biomarkers related to CVD were reported. Intervention studies indicated that introducing a better shift schedule into the workplace improved biomarkers (12) or introducing a worse shift schedule caused weight gain (13). There have been several long-term follow-up studies. Increased risks of obesity and weight gain among shift workers have been reported in a few studies (14-16). We reported on increased risk of the onset of diabetes mellitus and hypertension among shift workers in two cohort studies $(17,18)$. To reach conclusions on the

1 Department of Public Health, Kanazawa Medical University, Ishiakawa, Japan.

2 Kanazawa Medical University, Ishikawa, Japan.

3 Kanazawa University, Kanazawa, Japan.

4 Toyama University, Toyama, Japan.

5 Chiba University, Chiba, Japan.

Reprint requests to: Y Morikawa, Department of Epidemiology and Public Health, Kanazawa Medical University, 1-1 Daigaku, Uchinada-machi, Kahoku-gun, Ishikawa 920-0293, Japan. [E-mail: ymjr@kanazawa-med.ac.jp] 
health effects of shift work, we need more long-term prospective studies.

The aim of this study was to investigate the effects of shift work on changes in parameters related to metabolic disturbances, determined by a 10-year follow-up study. As factors related to changes in biomarkers, behavioral factors such as dietary intake, physical activity, alcohol intake, and smoking were also investigated.

\section{Study population and methods}

\section{Study population}

The cohort consisted of blue-collar workers ranging from 18 to 49 years of age in a Japanese zipper and sash factory. We followed the participants from 1993 to 2003 and investigated the changes in body mass index (BMI), blood pressure, serum cholesterol, and glycosylated hemoglobin A1c (HbAlc). The target population numbered 1807, and 1711 persons (94.7\%) could be followed to the end point. Among them, 182 changed to white-collar work during the 10 years; therefore, 1529 persons were used for the longitudinal analysis. A comparison of baseline data between the 1711 persons who could be followed and the 96 dropouts did not show any significant differences in the parameters evaluated.

\section{Occupations}

The work schedules were obtained from questionnaires administered in 1993 and 2003. The participants were classified into the following four groups according to the work schedule in 1993 and 2003: (i) day-day workers, those who did fixed daytime work in both 1993 and 2003, (ii) shift-day workers, those who did shift work in 1993 and transferred to fixed daytime work during the observation period, (iii) day-shift workers, those who did fixed daytime work in 1993 and transferred to shift work during the observational period, and (iv) shift-shift workers, those who did shift work in both 1993 and 2003. The number of participants in each group is shown in table 1 . The mean age of the shiftshift workers was the lowest among the four groups. The self-reported length of shift work up to 2003 was the longest for the shift-shift workers [19.0 (SD 8.2) years], followed by the shift-day workers [13.5 (SD 9.2) years], the day-shift workers [10.1 (SD 7.9) years], and the day-day workers [3.9 (SD 5.7) years]. Of the shift workers, $72.5 \%$ did rotating three-shift work, and the rest did rotating two-shift work. The three-shift workers rotated counterclockwise. Two-thirds of them were engaged in a noncontinuous shift system ( 5 day shifts, 5 night shifts, and 5 evening shifts), and one-third worked on a continuous-shift system (3- or 4-day shifts, 3- or 4-night shifts, and 3- or 4-evening shifts, with 1 rest day between successive shifts). Both rotating three-shift systems changed shifts at 0800,1630 , and 0015 or 0630 , 1300, and 2130. Certain jobs, such as those involving the operation of machines that melt, heat, mix, or cast, were routinely performed by the three-shift workers, while jobs involving processing or constructing aluminum products were done by fixed daytime workers or two-shift workers.

\section{Data collection}

The anthropometrical data and biomarkers were obtained in 1993 and 2003. Body mass index (BMI) was calculated as weight (kilograms) divided by height squared (meters $\left.{ }^{2}\right)$. Blood pressure was measured in a sitting position after rest for 5 minutes. Serum total cholesterol and $\mathrm{HbA} 1 \mathrm{c}$ were measured at the time of the health survey in both 1993 and 2003. Blood was not always taken as fasting samples. Health-related behavior was also recorded in 1993 and 2003 on questionnaires.

Table 1. Baseline characteristics of the groups of work schedule at baseline (1993) and the end point (2003). (BP = blood pressure, $\mathrm{HbAlc}=$ glycosylated hemoglobin A1c)

\begin{tabular}{|c|c|c|c|c|c|c|c|c|c|c|c|c|c|c|c|}
\hline \multirow[t]{2}{*}{$\begin{array}{l}\text { Work schedule } \\
\text { in } 1993 \text { and } 2003\end{array}$} & \multicolumn{2}{|c|}{$\begin{array}{l}\text { Age } \\
\text { (years) }\end{array}$} & \multicolumn{2}{|c|}{$\begin{array}{c}\text { Body mass } \\
\text { index } \\
\left(\mathrm{kg} / \mathrm{m}^{2}\right)\end{array}$} & \multicolumn{2}{|c|}{$\begin{array}{c}\text { Systolic } \\
\text { blood pressure } \\
(\mathrm{mm} \mathrm{Hg})\end{array}$} & \multicolumn{2}{|c|}{$\begin{array}{c}\text { Diastolic } \\
\text { blood pressure } \\
(\mathrm{mm} \mathrm{Hg})\end{array}$} & \multicolumn{2}{|c|}{$\begin{array}{c}\text { Total } \\
\text { cholesterol } \\
\text { (mmol/l) }\end{array}$} & \multicolumn{2}{|c|}{$\begin{array}{c}\mathrm{HbA1c} \\
(\%)\end{array}$} & \multirow[t]{2}{*}{$\begin{array}{l}\text { Current } \\
\text { smoker } \\
(\%)\end{array}$} & \multirow[t]{2}{*}{$\begin{array}{l}\text { Exer- } \\
\text { cise }^{\text {a }} \\
(\%)\end{array}$} & \multirow[t]{2}{*}{$\begin{array}{c}\text { Alcohol } \\
\text { consumption } \\
\text { (\%) }\end{array}$} \\
\hline & Mean & SD & Mean & SD & Mean & SD & Mean & SD & Mean & SD & Mean & SD & & & \\
\hline Day $\rightarrow$ day $(\mathrm{N}=712)$ & 36.4 & 8.2 & 22.39 & 2.76 & 118.3 & 13.4 & 71.6 & 10.2 & 5.07 & 0.86 & 4.98 & 0.57 & 67.5 & 66.6 & 41.9 \\
\hline Shift $\rightarrow$ day $(N=210)$ & 36.0 & 8.0 & 22.79 & 2.66 & 117.0 & 12.4 & 69.9 & 10.2 & 5.03 & 0.89 & 4.95 & 0.42 & 59.9 & 70.8 & 46.8 \\
\hline Day $\rightarrow$ shift $(\mathrm{N}=173)$ & 36.2 & 8.2 & 22.96 & 2.84 & 117.7 & 11.6 & 70.5 & 9.6 & 4.99 & 0.97 & 4.89 & 0.42 & 62.2 & 66.1 & 40.1 \\
\hline Shift $\rightarrow$ shift $(N=434)$ & 33.5 & 8.6 & 22.38 & 2.99 & 119.6 & 13.0 & 70.5 & 10.4 & 5.03 & 0.90 & 4.91 & 0.36 & 64.1 & 67.9 & 44.0 \\
\hline Total $(\mathrm{N}=1529)$ & 35.5 & 8.4 & 22.51 & 2.83 & 118.4 & 13.0 & 70.9 & 10.2 & 5.04 & 0.89 & 4.95 & 0.48 & 64.9 & 67.5 & 42.3 \\
\hline
\end{tabular}

\footnotetext{
a Less than once a week.
}

${ }^{\mathrm{b}}$ Almost every day. 
Nutritional intake was evaluated in 2003 using a self-administered diet history questionnaire (19). The total energy intake, the proportion of energy intake from protein, fat, and carbohydrates, and alcohol intake were calculated. The total energy expenditure during an entire day was evaluated in 2003 using a self-administered physical-activity questionnaire.

Table 1 shows the baseline characteristics by occupational group.

\section{Statistics}

The relationships between the change in parameters over 10 years, work schedule, and other confounding factors were analyzed using a multiple linear regression. The means of the changes in the parameters over 10 years after adjustment for age and other confounding factors were calculated in an analysis of covariance. The nutritional intake, energy expenditure, and prevalence of smokers and habitual drinkers in 2003 were compared among the groups using a cross-sectional analysis. Total calorie intake was compared among the occupational groups after adjustment for height in an analysis of covariance. The software package used for the analysis was SPSS, version 11.0 (SPSS Inc, Chicago IL, USA).

\section{Results}

Table 2 shows the relationships between changes in the parameters over a period of 10 years and the history of the work schedule by multiple linear regression analysis. Transferring from fixed daytime work to shift work (day-shift) and continuing shift work (shift-shift) were recognized as risk factors for an increase in BMI.
Continuing shift work (shift-shift) tended to increase total cholesterol $(\mathrm{P}=0.051)$. We could not find any significant relationship between the work schedules and $\mathrm{HbA1c}$ or blood pressure.

Table 3 shows the changes in each parameter over the 10-year period after adjustment for age and other confounding factors. The age-adjusted mean increase in BMI was the largest among the day-shift workers, followed by the shift-shift workers, the shift-day workers, and the day-day workers. The age-adjusted mean increase in BMI of the day-shift workers was $1.03 \mathrm{~kg} / \mathrm{m}^{2}$, significantly larger than that of the day-day workers and the shift-day workers. The shift-shift workers showed a significantly larger increase in BMI than the day-day workers. These statistical significances remained after adjustment for age and all other confounding factors, such as BMI, smoking, drinking, and leisure-time physical activity. The increase in total cholesterol tended to be higher among the shift-shift workers and day-shift workers, but the differences were not significant. Systolic blood pressure, diastolic blood pressure, and $\mathrm{HbA1c}$ did not differ among the groups.

Table 4 shows the mean nutritional intake and energy expenditure during an entire day and the prevalence of smoking by occupational group. The mean total calorie intake was calculated after adjustment for height because height is a major relevant factor of the necessary amount of total calories. There was a significant difference in total calorie intake among the groups. The calorie intake of the day-day workers was the least among the four groups, and the difference was statistically significant. However, the proportions of calories from protein, fat, and carbohydrates did not differ significantly among the groups. The prevalence of smoking, the upper quartile of alcohol intake, and energy expenditure did not differ among the groups.

Table 2. Relationship between changes in the parameters over a period of 10 years and work schedule and baseline characteristics in a multiple linear regression analysis. ( $\mathrm{HbA} 1 \mathrm{C}=$ glycosylated hemoglobin $\mathrm{A} 1 \mathrm{c}, \mathrm{Std} \beta=$ standardized beta, $\mathrm{NS}=$ no statistical significance)

\begin{tabular}{|c|c|c|c|c|c|c|c|c|c|c|}
\hline \multirow[t]{2}{*}{ Factors } & \multicolumn{2}{|c|}{$\begin{array}{l}\text { Body mass } \\
\text { index }\end{array}$} & \multicolumn{2}{|c|}{$\begin{array}{c}\text { Systolic } \\
\text { blood pressure }\end{array}$} & \multicolumn{2}{|c|}{$\begin{array}{l}\text { Diastolic } \\
\text { blood pressure }\end{array}$} & \multicolumn{2}{|c|}{$\begin{array}{c}\text { Total } \\
\text { cholesterol }\end{array}$} & \multicolumn{2}{|c|}{$\mathrm{HbA1c}$} \\
\hline & Std $\beta$ & P-value & Std $\beta$ & P-value & Std $\beta$ & P-value & Std $\beta$ & P-value & Std $\beta$ & P-value \\
\hline Age (year) & -0.143 & $<0.00$ & 0.237 & $<0.001$ & 0.106 & $<0.001$ & -0.170 & $<0.001$ & 0.048 & 0.077 \\
\hline Body mass index $\left(\mathrm{kg} / \mathrm{m}^{2}\right)$ & 0.369 & $<0.001$ & 0.193 & $<0.001$ & 0.119 & $<0.001$ & 0.075 & 0.004 & 0.116 & $<0.001$ \\
\hline Smoking (yes versus no) & 0.057 & 0.019 & -0.019 & NS & 0.032 & NS & 0.050 & NS & 0.058 & 0.030 \\
\hline $\begin{array}{l}\text { Leisure-time physical activity } \\
\text { (<1/week versus } \geq 1 / \text { week) }\end{array}$ & -0.020 & NS & 0.034 & NS & 0.033 & NS & 0.053 & 0.042 & -0.008 & NS \\
\hline Drinking (everyday versus other) & -0.023 & NS & NS & NS & 0.128 & $<0.001$ & 0.017 & NS & -0.028 & NS \\
\hline \multicolumn{11}{|l|}{ Work schedule ${ }^{a}$} \\
\hline Shift-day versus day-day & -0.014 & NS & -0.028 & NS & 0.039 & NS & 0.026 & NS & -0.010 & NS \\
\hline Day-shift versus day-day & 0.052 & 0.040 & -0.034 & NS & 0.006 & NS & 0.037 & NS & -0.006 & NS \\
\hline Shift-shift versus day-day & 0.061 & 0.019 & -0.019 & NS & 0.004 & NS & 0.055 & 0.051 & 0.033 & NS \\
\hline
\end{tabular}

a Day-day, shift-day, day-shift, shift-shift, categorized by work schedule in 1993 and 2003. 
Table 3. Comparison between the increase in the parameters over a 10-year period among the workers grouped by work schedule in an analysis of covariance. (NS = no statistical significance)

\begin{tabular}{|c|c|c|c|c|c|c|c|c|c|}
\hline & \multicolumn{9}{|c|}{ Work schedule in 1993 and 2003} \\
\hline & \multicolumn{2}{|c|}{ Day $\rightarrow$ day } & \multicolumn{2}{|c|}{ Shift $\rightarrow$ day } & \multicolumn{2}{|c|}{ Day $\rightarrow$ shift } & \multicolumn{2}{|c|}{ Shift $\rightarrow$ shift } & \multirow[t]{2}{*}{ P-value ${ }^{a}$} \\
\hline & Mean & SE & Mean & SE & Mean & SE & Mean & SE & \\
\hline \multicolumn{10}{|l|}{ Adjusted for age ${ }^{b}$} \\
\hline Body mass index $\left(\mathrm{kg} / \mathrm{m}^{2}\right)$ & 0.63 & 0.06 & 0.63 & 0.11 & 1.03 & $0.12^{c, d}$ & 0.88 & $0.07^{c}$ & 0.002 \\
\hline Systolic blood pressure (mmHg) & 3.4 & 0.6 & 3.9 & 1.1 & 2.9 & 1.2 & 2.5 & 0.8 & NS \\
\hline Diastolic blood pressure $(\mathrm{mmHg})$ & 5.5 & 0.4 & 6.9 & 0.8 & 6.0 & 0.9 & 5.4 & 0.6 & NS \\
\hline Total cholesterol $(\mathrm{mmol} / \mathrm{l})$ & 0.255 & 0.028 & 0.307 & 0.052 & 0.350 & 0.057 & 0.338 & 0.036 & NS \\
\hline Glycosylated hemaglobin A1c (\%) & 0.14 & 0.02 & 0.09 & 0.04 & 0.18 & 0.04 & 0.14 & 0.03 & NS \\
\hline \multicolumn{10}{|l|}{ Adjusted for confounding factors ${ }^{e}$} \\
\hline Body mass index $\left(\mathrm{kg} / \mathrm{m}^{2}\right)$ & 0.62 & 0.06 & 0.64 & 0.11 & 1.08 & $0.12^{c, d}$ & 0.89 & $0.07^{c}$ & 0.001 \\
\hline Systolic blood pressure (mmHg) & 3.5 & 0.6 & 3.5 & 1.1 & 2.6 & 1.2 & 2.6 & 0.8 & NS \\
\hline Diastolic blood pressure $(\mathrm{mmHg})$ & 5.4 & 0.4 & 6.8 & 0.8 & 5.9 & 0.9 & 5.6 & 0.6 & NS \\
\hline Total cholesterol (mmol/l) & 0.249 & 0.029 & 0.322 & 0.053 & 0.366 & 0.058 & 0.349 & 0.037 & 0.098 \\
\hline Glycosylated hemaglobin A1c (\%) & 0.13 & 0.02 & 0.09 & 0.04 & 0.13 & 0.04 & 0.18 & 0.03 & NS \\
\hline
\end{tabular}

a P-value: statistical significance between groups.

${ }^{\mathrm{b}}$ Estimated mean adjusted for age.

"Statistical significance $(P<0.05)$ compared with "day-day" workers.

d statistical significance $(P<0.05)$ compared with "shift-day" workers.

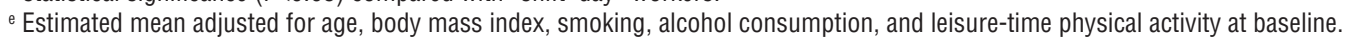

Table 4. Comparison of nutritional intake, energy consumption, and percentage of smokers and habitual drinkers at the end point (2003) among the workers when grouped by work schedule.

\begin{tabular}{|c|c|c|c|c|c|c|c|c|c|c|c|c|}
\hline \multirow{3}{*}{$\begin{array}{l}\text { Work } \\
\text { schedule } \\
\text { in } 1993 \\
\text { and } 2003\end{array}$} & \multicolumn{8}{|c|}{ Nutritional intake } & \multirow{2}{*}{\multicolumn{2}{|c|}{$\begin{array}{c}\text { Energy } \\
\text { expenditure } \\
\text { (metz) }\end{array}$}} & \multirow{3}{*}{$\begin{array}{c}\text { Consumers } \\
\text { of } \\
\text { alcohol }^{b}\end{array}$} & \multirow{3}{*}{$\begin{array}{l}\text { Current } \\
\text { smokers }\end{array}$} \\
\hline & \multicolumn{2}{|c|}{$\begin{array}{l}\text { Total calorie } \\
\text { (kcal/day) }^{a}\end{array}$} & \multicolumn{2}{|c|}{$\begin{array}{l}\text { Calorie from } \\
\text { protein }(\%)\end{array}$} & \multicolumn{2}{|c|}{$\begin{array}{l}\text { Calorie from } \\
\text { fat }(\%)\end{array}$} & \multicolumn{2}{|c|}{$\begin{array}{c}\text { Calorie from } \\
\text { carbohydrate (\%) }\end{array}$} & & & & \\
\hline & Mean & SD & Mean & SD & Mean & SD & Mean & SD & Mean & SD & & \\
\hline Day $\rightarrow$ day & 2117 & 27 & 11.0 & 2.1 & 19.9 & 6.4 & 60.1 & 8.7 & 40.3 & 0.3 & 23.9 & 57.3 \\
\hline Shift $\rightarrow$ day & $2229^{c}$ & 49 & 10.8 & 1.8 & 20.6 & 6.5 & 59.9 & 8.5 & 40.2 & 0.5 & 24.1 & 47.2 \\
\hline Day $\rightarrow$ shift & $2252^{c}$ & 34 & 11.0 & 2.2 & 20.8 & 6.7 & 59.4 & 8.6 & 40.7 & 0.3 & 24.4 & 54.9 \\
\hline Shift $\rightarrow$ shift & $2362^{c}$ & 56 & 11.1 & 2.0 & 20.0 & 7.4 & 59.8 & 9.6 & 41.0 & 0.5 & 32.2 & 52.6 \\
\hline
\end{tabular}

a Estimated mean (and standard error of the mean) adjusted for height in an analysis of covariance.

b In upper quartile of alcohol intake (>34 ml/day).

c $\mathrm{P}<0.05$ in comparison with the day-day group; $\mathrm{P}$-value $<0.001$ for ?.

\section{Discussion}

The purpose of this study was to determine the influence of shift work on biomarkers related to CVD. In studies on the effect of shift work on health, there have been some methodological problems regarding selection into shift work and selection out of shift work. Some studies have suggested that workers who drop out of shift work have a higher risk of CVD than workers who continue in shift work $(19,20)$. Thus, we analyzed data after grouping workers by their work schedule at baseline and at the end of an observation period of 10 years [the workers who continued shift work (shift-shift), those who continued fixed daytime work (day-day), and those who changed work schedules during the observational period (day-shift and shift-day)]. The drawback of this study was the lack of a history on the work schedule between the baseline and the end point. In this company, however, selection into shift work or selection out of shift work had been decided mainly by the characteristics of each worksite instead of by individual circumstances, and changes were not frequently introduced into the work schedule. The entire length of the shift work was the longest among the shift-shift workers, followed by that of the shift-day workers, the day-shift workers, and the day-day workers. Therefore, the categorization used in 
this analysis was considered to reflect the transition of work during the observational period and the history of shift work over the entire worklife. The definition of "shift work" in this analysis included both two-shift work and three-shift work to simplify the grouping by work schedule at baseline and the last year. In addition, the baseline data of the workers who dropped out of this follow-up study did not differ from those of the persons who were followed.

According to the results of this study, the variable most influenced by shift work was BMI. The largest increase in BMI was found among the workers who transferred from daytime work to shift work during the observational period (day-shift), followed by the increase among the workers who continued shift work (shift-shift). The significant increase in BMI among them remained after adjustment for other possible confounding factors, such as age, baseline BMI, and healthrelated behavior. Because several studies on this topic have used the cohort design, our data are important for showing a positive relationship between weight gain and shift work in a long-term cohort study. A short-term follow-up study reported that BMI decreased significantly among shift workers when they were compared with daytime workers after 1 year from the start of a new job (10). On the other hand, Niedhammer et al (15) found a positive relationship between shift work and excess weight or weight gain in a 10-year follow-up study. Gieliebter et al (14) also came to a similar conclusion, although their data regarding weight gain were selfreported.

Recent reports have tended to show a higher prevalence of metabolic disturbances among shift workers (4-9), but some cohort studies have also been carried out. In our current study, we did not find any significant changes in biomarkers among shift workers when these workers were compared with daytime workers, although total cholesterol tended to increase more among the workers who continued shift work than among the workers who continued fixed daytime work. We reported that male blue-collar shift workers had a significantly higher risk of diabetes mellitus when compared with white-collar workers, but they did not have a significantly higher risk than blue-collar daytime workers (18). We have also reported an increased risk for the onset of hypertension among shift workers of younger ages in cohort studies (17). The effects of shift work on health may appear at different points for each parameter. Weight gain is one of the major risk factors for an increase in blood pressure and lipids and a decrease in glucose tolerance. Therefore, the greater increase in BMI among shift workers would have an influence on biological data after a period of time.

In our current study, the greater increase in BMI among the workers who continued shift work and the workers who transferred from daytime work to shift work may have been caused by health-related behavior. However, the smoking and drinking habits of the groups did not differ at baseline or at the end point. Amelsvort et al (10) reported that the number of cigarettes smoked per workday increased significantly among shift workers in a comparison with daytime workers, as shown in a 1year follow-up study. However, overall, the influences of shift work on smoking and drinking habits have been found to be inconsistent (1).

We found a significant difference in the total calorie intake among the groups of workers in our study at the end point. The workers who continued to work shifts (shift-shift) consumed the highest number of calories, followed by the workers who transferred from daytime work to shift work (day-shift). Whether these differences were influenced by work schedule was unknown because we did not have data on the workers' diets at baseline. Studies into the influence of shift work on eating habits (21-23) have reported that shift work causes a circadian redistribution of food and that there is a tendency towards the consumption of cold and fast food, but the overall calorie intake did not differ between the shifts of each worker.

In summary, our results suggest that shift work is related to weight gain. This effect was more prominent among those who moved to shift work from daytime work. Some changes in dietary habits during the adaptation to shift work may be related to weight gain. In this cohort study, we did not find significant increases in blood pressure, serum lipid, or glycosylated hemoglobin. An increase in weight gain among shift workers would have had an influence on the biological data after a period of time.

\section{References}

1. Bøggild H, Knutsson A. Shift work, risk factors and cardiovascular disease [review]. Scand J Work Environ Health. 1999;25(2):85-99.

2. Knutsson A. Health disorders of shift workers. Occup Med. 2003;53:103-8.

3. Kristensen TS. Cardiovascular disease and the work environment: a critical review of the epidemiologic literature on nonchemical factors [review]. Scand J Work Environ. 1989;15:165-75.

4. Karlsson B, Knutsson A, Lindahl B. Is there an association between shift work and having a metabolic syndrome? Results from a population based study of 27,485 people. Occup Environ Med. 2001;58(11):747-52.

5. Nagaya T, Yoshida H, Takahashi H, Kawai M. Markers of insulin resistance in day and shift workers aged 30-59 years. Int Arch Occup Environ Health. 2002;75:562-8.

6. Parkes KR. Shift work and age as interactive predictors of body mass index among offshore workers. Scand J Work Environ Health. 2002;28(1):64-71. 
7. Di Lorenzo L, De Pergola G, Zocchetti C, L'Abbate N, Basso A, Pannacciulli $\mathrm{N}$ et al. Effect of shift work on body mass index: results of a study performed in 319 glucose-tolerant men working in a southern Italian industry. Int J Obes. 2003;27:1353-58.

8. Karlsson BH, Knutsson AK, Lindahl BO, Alfredsson LS. Metabolic disturbances in male workers with rotating three-shift work. Results of the WOLF study. Int Arch Occup Environ Health. 2003;76:424-30.

9. Ha M, Park J. Shiftwork and metabolic risk factors of cardiovascular disease. J Occup Health. 2005;47:89-95.

10. Amelsvoort LGPM, Schouten EG, Kok FJ. Impact of one year of shift work on cardiovascular disease risk factors. J Occup Environ Med. 2004;46:699-706.

11. Theorell T, Åkerstedt T. Day and night work: changes in cholesterol, uric acid, glucose and potassium in serum and in circadian patterns. Acta Med Scand. 1976;200:47-53.

12. Bøggild H, Jeppesen HJ. Intervention in shift scheduling and changes in biomarkers of heart disease in hospital wards. Scand J Work Environ Health. 2001;21(2):87-96.

13. Yamada Y, Noborisaka Y, Suzuki H, Honda M, Yamada S. Excessive fatigue and weight gain among cleanroom workers after changing from an 8-hour to a 12-hour shift. Scand J Work Environ Health. 2001;27(5):318-26.

14. Geliebter A, Gluck ME, Tanowitz M, Aronoff NJ, Zammit GK. Work-shift period and weight change. Nutrition. 2000;16:279.

15. Neidhammer I, Lert F, Marne MJ. Prevalence of overweight and weight gain in relation to night work in nurses' cohort. Int J Obes Relat Metab Disord 1996;20:625-33.
16. Amelsvoort LGPM, Schouten EG, Kok FJ. Duration of shiftwork related to body mass index and waist to hip ratio. Int $\mathrm{J}$ Obes. 1999;23:973-8.

17. Morikawa $\mathrm{Y}$, Nakagawa $\mathrm{H}$, Miura K, Ishizaki M, Tabata M, Nishijo M, et al. Relationship between shift work and onset of hypertension in a cohort of manual workers. Scand J Work Environ Health. 1999;25(2):100-4.

18. Morikawa Y, Nakagawa H, Miura K, Soyama Y, Ishizaki M, Kido T, et al. Shift work and the risk of diabetes mellitus among Japanese male factory workers. Scand J Work Environ Health. 2005;31(3):179-83.

19. Sasaki S, Kim MK. Validation of self-administered dietary assessment questionnaires developed for Japanese subjects: systemic review [review]. J Community Nutr. 2003;5:83-92.

19. Koller M. Health risks related to shift work, an example of time-contingent effects of long-term stress. Int Arch Occup Environ Health. 1983;53:59-75.

20. Angersbach D, Kanuth P, Loskant H, Karvonen MJ, Undeutsh $\mathrm{K}$, Ruftenfranz J. A retrospective cohort study comparing complaints and diseases in day and shift workers. Int Arch Occup Environ Health. 1980;45:127-40.

21. Tepas DI. Do eating and drinking habits interact with work schedule variables? Work Stress 1990;4:203-11.

22. Lennernas M, Hambraeus L, Åkerstedt T. Shift related dietary intake in day and shift workers. Appetite. 1995;25:253-65.

23. Waterhouse J, Buckley P, Edwards B, Reilly T. Measurement of, and some reasons for, differences in eating habits between night and day workers. Chronobiol Int. 2003;20:1075-92.

Received for publication: 6 April 2006 